\title{
Assessment of Legislation on Budget implementation in Kisii County Government, Kenya
}

\author{
Joseph Wesonga Awire*1, Simon Nyakwara, ${ }^{* 2}$ \\ 1. Masters Degree in Business Administration and Management of Mount Kenya University. \\ 2. Doctor of Philosophy\& Director at Kisii Campus of Mount Kenya University.
}

\begin{abstract}
Budgeting is a vital tool in organizations for directing activities and employees' efforts toward the organization's common objectives. Budgeted results communicate to employees the organization's expectations regarding their job performance, which is evaluated based on some comparison of actual versus budgeted results. Kisii County is no special case to spending plan failure and its execution which can be measured in terms of achievement needs. The purpose of the research is to examine the factors affecting budget implementation in county governments in Kenya by taking a selected case of Kisii County. The specific objectives of the study were: To examine the effect of legislation on budget implementation in Kisii county government, to examine the influence of public participation affects budget implementation in Kisii county government, to find out how human resource capacity affects budget implementation in Kisii county government and to examine the influence of leadership effectiveness affects budget implementation in Kisii county government. The study utilized a contextual investigation as its examination outline. A contextual investigation approach is appropriate to decide the elements that make a specific passage system great for the association under examination. The study population was representatives and authorities of the Kisii County. A sample size of 105 respondents was used in the study while questionnaire was used as research tool. The study established that legislation, public participation, human resource and leadership efficiency positively and significantly influenced budget implementation in Kisii County. The study recommends that the county assembly should speed up the sanctioning of all enactments relating to county government funds and administration conveyance to give an appropriate lawful structure to spending execution. The County governments should create rules on open support for Economic and Social Rights Center, 2013 which demands the general population inclusion to incorporate their views in the County Integrated Development Plan; the arrangement of the County Fiscal Strategy Paper and survey of the spending gauges by the County Assembly.

Key Words: Legislation, Budget implementation, Kisii County Government, Kenya.
\end{abstract}

DOI: $10.7176 /$ RJFA/10-14-12

Publication date:July $31^{\text {st }} 2019$

\subsection{Background to the study}

Spending plans are monetary diagrams that measure a company's gets ready for a future period (Schick, 1999). It is an itemized design demonstrating the obtaining and use of money related and different assets in a given period. Financial plan is a standard in which the real execution can be thought about and measured; it stipulates which exercises and projects ought to be effectively sought after. Administration in both private and open part is relied upon to indicate foreseen incomes and use. Spending plans in an association goes about as an instrument for viable arranging (Flamholtz, 1983).

Robinson (2007), in developing countries, the organization of budgetary system is subordinated to the problems of eliminating the remnants of feudalism and colonialism. In view of the weakness of the inadequacy of their capital, the most important measures in the areas of economics and culture in these countries such as India, the Arab Republic of Egypt and others were financed through the state budget. 2 At the same time, in order to involve broad layers of the population in the accomplishment of national economic and political tasks, the governments of these countries follow a policy of developing the plan and budget capital of local bodies.

The principle capacity of a financial plan in any association is for arranging and controlling, to accomplish hierarchical objectives and targets (Schick, 1999). Spending execution has been for an excessive number of years seen fundamentally as a procedure worried about the pre review of bank bills and strategies of their installment (Berg and Skogley, 2002). In any case, in all actuality spending usage and related parts of money administration are more than the aggregate of the above components (Zimmerman, 2003).

The new Kenyan constitution proclaimed on $27^{\text {th }}$ August 2010 presented changes in the way the nation might be administered. This incorporate the general population's support in the activity of proprietors of the state and in settling on choices that impact them has been ensured by building up an administration at the region level. The constitution presented changes in spending execution process both at the national and region level. Article 201 of the constitution states some primary open back qualities including the need to guarantee transparency and 
responsibility in all open monetary issues. Open interest is featured in the whole spending execution and basic leadership.

New legitimate casing work established by the new constitution, regions are encountering challenges in executing spending plans and subsequently there are big dissimilarity between the province spending plans and achievements. A few surveys of PFM in creating nations demonstrate that nations score preferable on spending planning over on spending execution markers (Andrews, 2008). As indicated by Sayeh (2013), large scale financial solidification in Kenya was joined by changes in fundamental spending capacities. A key test in Kenya will be to execute basic PFM hones in the new Counties that have been set up bringing about the decentralization activity reflected in the new constitution. Suberu (2010) states that for any association to perform successfully, spending plan and planning ought to enable operational use of existing assets enhance basic leadership, give a seat check to quantify and control execution, enhance correspondence and investigation in the association and create understanding between supervisors about objectives and destinations.

As indicated by The Controller's report (2001) on a vital level, planning elucidates organization focused needs, points of interest and techniques for what's to come. It is additionally a system for putting the foundation needs by distributing limited assets to those endeavors that authorities accept to be the most essential and apportioning it to those ranges considered less fundamental (Goldstein, 2005). Intrigue fills in as an instrument for closure the gap between close-by government, private zone, regular society, and the general gathering by working up a run of the mill understanding about neighborhood situation, needs and activities (Moseti, 2010). The purpose of open collaboration is to progress shared cognizance, straightforwardness and obligation in organization and settle on duty regarding decisions, activities and errand. Interest in spending execution grants limited individuals to give finds in the development exercises. It mulls over full consideration of standard people from the gathering in fundamental initiative, orchestrating, arranging, dealing with and executing progression action that impact them (Tshabalala and Lombard, 2009).

According to the Government of Kenya (2010) the constitution develops open collaboration as one of the important rights of the Kenyan people. Segment 11 of the constitution, which discusses Devolved governments conclusively; express the criticalness of national enthusiasm for the endeavors of government. Article 196 on open help and area gathering powers, advantages and resistances evidently stipulate that the local government ought to support open venture and commitment in the regulatory and diverse business of the region get together and its committees (GoK 2010).

Article 174 of the constitution gives the vitality of self-organization to all-inclusive community of Kenya and advances the help of the locals in exercise of the vitality of the state and in settling on decisions on issues that impact. Planning is a basic movement of any administration world over. Through the procedure, the legislature can decipher the utilization of physical assets to meet national needs and satisfy their guarantee to the electorate. Subjects on their part expect the way toward planning to be reasonable, straightforward, and impartial (OECD, 2007). 10 years prior, the reasoning on planning among technocrats, macroeconomic approach producers and scholastics supported for a procedure that was embraced solely by technocrats in the Ministries of Finance and Ministries of Planning. The inclination was to do a procedure without "governmental issues" (World Bank, 2002) As per Olurankise (2012), budget making and spending usage includes the procedure of distinguishing proof of open needs by the political procedure, by financial examination with the general advancement goals. Once a financial plan has been affirmed by the council, the legislature sets out on the testing undertaking of spending reserves.

Spending open supports successfully to meet expressed strategy targets while guaranteeing an incentive for cash is frequently only as challenging than arranging how to spend it (Rebecca et al, 2011).

The Kisii County government was framed under the domain of the new constitution and it successfully came into operation in March 2013 after the general election. Like any other government, the Kisii area government executes its strategies through its financial plan.

In the same class as the financial backing may look as far as arrangement and substance there are extensive variety of dissimilarity amongst spending plan and achievements. This has brought the requirement for the present examination to inspect the elements influencing spending usage in region governments in Kenya by taking a chose instance of Kisii County.

\subsection{Statement of the problem}

The financial plan whether it is for an open organization or for a private increase situated organization is a fundamental and effective apparatus in administration and fills in as a device for arranging and controlling the utilization of restricted money related resources. With the operation of the new arrangement of administration in Kenya, the national government is confronted with an expanded request to build its subsidizing to province governments among constrained assets. This calls for proficiency in usage of assets at the province level which must be accomplished by great spending execution. In any case, in the same class as the region spending plan might be as far as planning and substance, provinces may not be extremely strict in complying with the financial plans. Accordingly, there are wide scope of difference amongst spending plan and achievements. Kisii County is 
no special case to spending plan failure and its execution which can be measured in terms of achievement needs. Consequently, this gives the requirement for the present assessment of factors influencing spending usage in province governments in Kenya by taking a chose instance of Kisii County.

\subsection{LITERATURE REVIEW}

\subsection{Legislation on Budget Implementation}

According to Maheshwari (2006) budget is the money that is available to an organization and a plan of how it will be spent over a period of time. According to Brown et al (2001), budget as a plan quantified in monetary terms prepared and approved prior to defined period of time, usually shows planned income to be generated and expenditure to be incurred during that period and the capital to be employed to attack a given objective. Lucey (2009) agrees that although many of the principles of budgeting apply equally to non-profit organization and profit seeking organization a key different is that the latter organizations budgets focus on the relationship between expenditure (input) and sales revenue (output). In non-profit organization outputs are much more difficult to measure hence traditionally budgeting has been concerned with making sure that for each expenditure heading actual spending does not exceed the budget authorized cash. In recent years, much attention has been given to the strengthening of budget and planning and their interrelationship in developing countries including Tanzania. The advocacy of this has come from prominent international agencies as World Bank and International Monetary Fund. These agencies are all interested in encouraging developing and underdeveloped countries to improve their budget practice. All these show the importance attached to budget as a management process.

Participation in budgeting (Bottom-up Budget) Responsibility accounting assumes that manager' influence costs and that the best way of controlling these costs is to hold these managers responsible for the costs they influence (Garrison, Noreen \& Seal, 2003). This means that bottom line or sectional managers are required to develop their own budgets and are then held responsible for meeting their targets. Bottom-up budget is most useful when lowerlevel managers actively are involved or engaged in the budgeting process. Participation adds reliability to the budgeting process and creates greater commitment and accountability toward the budget, as budgets are set by management but the people to realize the budget standards are the staff. Drury (2001) highlights that any control process which does not recognize human nature and its requirements may be counterproductive. That is participation must be emphasized; it has a huge potential for encouraging communication of organizational goals, improving attitude towards budgeting system and increasing subsequent performance. Hilton, et al. (2000) demonstrated, participative approach to budgeting since it can be more effective and people may be more motivated to achieve budgetary goals if they have consulted in the budget preparation. Prior studies on the relationship between participative budgeting and performance have provided diverse results. Covaleski et al. (2003) found that, there exists a positive relationship between budget participation and performance while other scholars found negative relationship. All in all, the key to successful performance necessitate the involvement of managers and personnel at all levels as it helps to ensure departments will attain targets and operate within the budget. Controller must be able to negotiate and communicate effectively with people in all levels of an organization. Issues relating to participation in budget process have been well discussed by Sullu (1991) in his paper on "Behavioural Dimension of Budgetary Planning \& Control". 16 He emphasized that budgeting is not mechanistic technical procedure; its success is totally dependent upon the goodwill and co-operation of the participants. Without this, budgeting will become a mere paper exercise with no real impact on the operations of the organization. In the process he added that; it is quite wrong to ignore human factor. If human factor and its elements will be lacking in the budget process, then the whole process will be useless and will appear as a paperwork that will not help any organization. This statement highlights that; the central behavioural issue is the degree of participation in the preparation of budget that upper-level management is willing to entrust to middleand-lower managers. This has become one of the most important aspects of the budgetary process since in reality the approved budget represents a consensus and bargained commitment among many people in the organization. 2.2 Preparation of Budget in the organization

According to Lucey (1996), a budget is prepared and approved before its implementation showing income, expenditure and capital to be employed. It may be drawn up showing incremental effects of former budgeted or actual figures, or compiled by zero-based budgeting approach. As Blocher et al (2002) argue that, budgets help to allocate resources, coordinate operations and provide a means for performance measurement. Furthermore, budgeting involves planning for various cost generating activities and revenue producing of an organization. The importance of budgeting is emphasized by an old saying, "Failing to plan is like planning to fail". Thus, budgeting is essentially financial planning or planning for performance.

As it is known that budget is the vehicle for addressing objectives, strategies and problems in the most intelligent way. It is the vehicle which gives reality to the organization objectives and strategies and should reflect the organization considered decision strategy. The organization of Dire Dawa city municipality has its own budget that prepared in their organization. Also the organization have manual budget. As interview response, indicated that the finance department manager, the organization has been preparing a budget since it was established. Based 
on the respondent responses for the question was budget prepared for one year /annual and recurrent budget type is the known budget.

\subsection{Public Participation on Budget Implementation}

Kenya's 2010 Constitution and succeeding enactment, for example, the County Governments Act and the Public Finance Management Act, require open involment in issues of open fund. While there are many references to open support in these laws, most are obscure and contain no further direction. There is one noteworthy avoidance to this, notwithstanding, which is the particular commitment that each area should set up a County Budget and Economic Forum (CBEF). The CBEF is approved by the Public Finance Management (PFM) Act, 2012. The Act,which states that regions might make these gatherings keeping in mind the end goal to give an intend to discussionby the province government on readiness of district strateic plans, Review and Outlook Paper for the area ,the County Fiscal Strategy Paper, and the Budget; and matters identifying with planning, money related administration and the economy at the region level (Lakin, 2013).

Studies directed by the Haggard and Webb (1994) contend that thus, government officials delegated decisionproduction expert to technocrats who were protected from weight and impedance from intrigue gatherings, the assembly, and bureaucratic procedures. Observational discoveries on this issue were in opposition to this contention. Concentrates by the World Bank (2002) discovered that a more comprehensive approach with key partners including people in general would upgrade the maintainability of arrangements and enhance their prospects for usage achievement.

Over the most recent two decades, some Latin American nations have actualized participatory planning as a method for fusing native's points of view into spending making keeping in mind the end goal to expand resident's entitlement to take part and improve straightforwardness. Some of these nations incorporate Argentina, Bolivia, Brazil, Chile, Colombia, Ecuador, El Salvador, Dominican republic, Guatemala, Mexico, Paraguay, Nicaragua, Peru, Uruguay, and Venezuela. By the year 2007, 2,500 nearby governments in these nations were executing participatory planning with awesome achievement (ELLA, 2012). As of late, open support in thebudgeting process is established upon standards, for example, Legitimacy, Accountability and straightforwardness in basic leadership, inclusivity and reasonableness (Economic and Social Rights Center, 2013).

Kenya is among the main nations in Africa other than South Africa to make open interest in planning an established prerequisite (Economic and Social Rights Center 2013). Kenyan constitution authorized in 52010 digs out in the open investment as one of the principal benefits of the Kenyan individuals. Section 11 on Devolved governments particularly explains the significance of native cooperation in the undertakings of government. This is illustrated in supplement five. Article 196 on open investment and area get together powers, benefits and resistances plainly stipulate that the province government might encourage open support and association in the administrative and different business of the region get together and its boards of trustees (Government of Kenya, 2010).

Article 201 of the Kenyan constitution explains a portion of the key open fund standards including the requirement for straightforwardness out in the open back issues. The standards likewise accentuate that open support might be advanced in the basic leadership and planning process (National Taxpayers Association, 2013) The Kenya's Public Financial Management (PFM) Act, which was marked into law by the President in July 2012, gives the lawful system to the investment of the general population in planning and guaranteeing responsibility in budgetary administration. The Bill makes a few references to the need to guarantee open support in various money related administration forms. (Legislature of Kenya, 2014) the Parliamentary Budget Office is relied upon to "watch the rule of open support in budgetary issues" (10:2) The Treasury is expetedto "seek after and think about the feelings of people in general" in putting forth the Budget Policy Expression consistently (25:5). This demonstration over and over makes reference to the part and criticalness of general society cooperation in planning and budgetary administration. The PFM demonstration additionally made the County Budget and Economic Forum (CBEF) whose central capacity is to assemble open interviews on budgetary issues at the district level (Government of Kenya, 2014).

The sanctioning of the CDF Act of 2003 and the LATF show the best exertion of the Kenyan government at decentralizing assets at the voting demographic level and advancing grassroots improvement arranging where groups take an interest in the ID, outline, usage, and assessment. (Establishment of Economic Affairs, 2012) in the usage of the Constituency Development Fund (CDF) in Kenya, open support is acknowledged through investment in boards. Individuals from people in general contribution in the execution of CDF ventures has been done through the Project Management Committees (PMCs) which comprise of individuals from the general population who oversee and regulate the execution of individual CDF ventures (Institute of Economic Affairs 2012). Upon the order of the new constitution and the foundation of region governments, the province planning process was likewise anticipated that would be adjusted to the constitution as for open support. The constitution is certain that the County governments must include people in general in basic leadership, incorporating into the planning procedure (Government of Kenya 2010). According to Economic and Social Rights Center (2013), key zones where the general population inclusion is normal incorporate the readiness of the County Integrated Development Plan; the arrangement of the County Fiscal Strategy Paper and survey of the spending gauges by the County Assembly. 
To satisfy this desire, County governments are required to create rules on open support (Economic and Social Rights Center, 2013).

Kenyans have profound and long-lasting worries about the routes in which assets have been circulated across the nation. Numerous areas and individuals feel that they have been surrendered by a solid focal administration. The cure in the 2010 Constitution is, from one viewpoint, devolution of energy to bring down level government and, then again, endeavors to open up establishments at all levels and surge the open doors for open support, and more prominent checks by new bodies, for example, the Controller of Budget (Public Finance Management-PFM, 2013). It takes after from this that open commitment is to a limited extent about bringing into line the necessities and needs of general society all the more intimately with the decisions of government authorities. This suggests open interest must occur at the detailing and endorsement periods of the financial plan, when urgencies are being set. At this progression, open commitment can support basic leadership by passing on data about open requests to the consideration of lawmakers as they organize their spending. This can prompt a more evenhanded dispersion of assets (Lakin, 2013).

Likewise, concerns emerging from corruption and inability to legitimize for assets over the span of spending plan execution recommend that open investment in Kenya is additionally urgent amid spending execution and when spending execution is evaluated. The overall population has a very important part to play that supplements the County Assembly and different bodies. Data that the general population holds about the success of open expenditure on the grass root can help in advising the oversight procedure and enhance spending usage. It is concluded from this that open cooperation is indispensable at all means of the spending procedure. Open support is likewise about building the authenticity and validity of the government. By drawing in heartily with nationals, government authorities can guarantee support for their projects and construct trust in the capability of the administration. This can inspire investors to confer reserves, urge natives to pay expenses, and benefactors to top up existing wellsprings of pay. In the event that we consider public interest as a device for building authenticity and believability, this indicates that powerful cooperation will need transparency and an effecient criticism circle in which subject's requests are answered to, and reasons are accommodated consolidating or not joining them (Ebdon and Franklin, 2005).

At the point when individuals contemplate on open investment, they regularly consider gatherings. An open discussion is generally open to any individual who needs to go to. Presently, we realize that albeit open discussions are interested in everybody, not every person comes. The general populations who go to are here and there the general population, who live nearest to the setting, or the individuals who get earlier information about the discussion, or the general population who can manage the cost of time off the work schedule to go to. It in this way takes after that even an open gathering who exclude everybody. This can be partly moderated by enabling individuals to send composed entries or by holding open discussions at the most minimal level conceivable. There are different approaches to compose open verbal confrontation past merely holding open discussions. For example, even in Kenya's own insight with participatory planning, the Local Authority Service Delivery Action Plan (LASDAP), open exchange was sorted out at numerous levels and assignments were utilized. At first, conference gatherings were called at the ward level. At that point, two individuals (one male and one female) were selected to speak to the ward at the neighborhood specialist level "agreement" gatherings. This approach, which was obtained partially from Brazil, can be reached out to different levels, with selections from the most reduced levels (e.g., town) to the most noteworthy (e.g., area, or even national). This can enable individuals to take part more extensively regardless of the possibility that they are absent (Nivek, 2012).

Experience from Kenya and all over the world recommends that building up aparticipatory systems is faced with difficulties, and interest activities frequently flounder. It's imperative to be aware of these difficulties from the earliest starting point keeping in mind the end goal to in any event endeavor to plan for them.Access to data and comprehension is regularly a test. Spending data is oftenlydifficult to accomplish, and difficult to get it. On the off chance that contribution components are to work, there must be a greatextent of straightforwardness, however existinginformation ought to likewise be delivered in a way that is basic and straightforward. In different settings, extraordinary activities have been taken to guarantee that data is accessible and is in a simple to utilize design. In the Philippines, the Budget Partnership Agreements between common society and government organizations incorporate particular revelation necessities (e.g., spending data from the most recent five years) to encourage support. In Burlington, Iowa (USA), the administration chooses a Citizen Budget Education Committee to guarantee that spending data is rearranged for open utilization. Essentially in German towns, for example, Hilden, the town readies a pamphlet with key spending information, and afterward there are data remains at open gatherings themselves where individuals can get additional data (Ebdon and Franklin, 2005).

\subsection{Leadership on Budget Implementation}

The utilization of spending plan as an instrument for arranging and control is all inclusive in contemporary associations particularly in the business specialty units. Be that as it may, for the financial backing to prevail in its main goal of upgrading the estimation of the business, thehuman factor is of boss significance. In dealing with the 
unpredictable idea of HR in acknowledging authoritative targets, there is no all around known administration style.It is differing of conclusions as to which type of initiative style is the best (Adefila et al., 2007).

Authority and spending plan are two principle administration ideas that have been extensively examined by administration and bookkeeping researchers, for instance, (Coad, 1999; Arowomole, 1995). In any case, the aftereffects of the examinations yet stay hard to sum up in theapplication similarly as their persisting authenticity is as yet sketchy. Every year, numerous associations everywhere throughout the world, record exasperating negative fluctuations when genuine outcomes are contrasted and spending plans. With theunabated experience of these negative fluctuations, business associations have a tendency to gather substantial misfortunes in their business portions. For the most part, fizzled spending plans are ascribed to aleadership issue. Consequently, many undertakings choose for coming full circle in scaling down, rebuilding, and diligent deviations in authority. At the point when two of the related meanings of administration are examined, the thoughts of initiative and spending plan progress toward becoming morevibrant. Administration has been all around characterized as completing things through others (Robbins\& Coulter, 2000).

This is an administration focused definition. A similar idea implies arranging, sorting out, controlling, and coordinating a procedure situated view. Natural in the main definition is a conspicuous identity (predominant) around whom the current obligation rotates. In any case, the supervisor wants to utilize some skillsin perspective of the natural second thoughts that undermine and potentially baffle administration's operations.Dominant among these is spending plan, an instrument for arranging andcontrolling the organization'sactivities with the goal that they do not have no ability to know east from west and decrease the effect of the demon (vulnerability) that stalks the mission of each association. Nonetheless, while thebudget is complete (can be measured fiscally or quantitatively); initiative is an unpredictable behavioralconcept in a wide continuum of available complex occasions. Various authority styles are accessible for the achievement of a particular spending objective. While supervisors and bookkeepers at times differ on the calculation of the financial plan, once the structure for its arranging has been foreordained (e.g. by what extent should consequent year's deals be over previousyear's aggregate?), the authority style grasped by a predominant frequently incites intense and conflictingopinions from directors and bookkeeping analysts alike. Thereforethe initiative style grasped by an unrivaled impacts spending arrangement and execution.

As indicated by Brownell (2003), authority can be depicted as "a lively procedure of overseeing agroup whereby an individual impacts the others to contribute eagerly to the achievement of gathering obligations in a given circumstance. Following the above contention, Goleman (2000) states that: Since the Industrial Revolution, organizations havewanted a mix of initiative aptitudes like exclusive requirements of administrative skills, organize and deal with their staff, having the capacity to plan and spending plan, control and tackle issues. Today, in any case, quick changes in the earth may have changed the prerequisites for fruitful initiative. Pioneers and directors are expected to realize changes to remain in front of thecompetition while then again keeping up a solidness of business operations. To do this, they require to make anenvironment for execution, including adaptability, duty, and exclusive expectations. As indicated by Adefila et al. (2007), kind of authority style embraced in planning impacts the execution of an association. In particular, the participative initiative style was exaggerated over alternate sorts of authority concerning sway on execution. Their investigation likewise uncovered that basic leadership in planning ought to be fair whether in broad daylight or privately owned businesses. Adefila et al. (2007), discoveries are at change with the conclusion came to by Jaggi (1973) that definitive style yields high occupation fulfillment in creating nations, which suggests a high spending execution. On the off chance that theauthoritarian style has a noteworthy positive effect on planning, this is steady, winding up less articulated. A conceivable reason is that the estimation of the present workers is progressed, particularly with reference to scholarly profundity attributable to high scholastic and expert accomplishments. The present chiefs of industry would improve to receive equitable or participative standards in corporate administration. An examination completed in Nigeria showed that, generally speaking in Nigerian organizations inconveniences of spending plans were getting to be noticeably disagreeable. A participatory state in which upper-administration evokes the subordinates' contributions previously the endorsement of spending plans had been much in vogue. In the event that the subordinate incorporates a wide slack with the financial plan, the super shouldn't attempt a self-ruling alteration. This involves an astute push to persuade and procure veritable acknowledgment of the subordinate. After spending plan, endorsement comes usage of the arrangement (Adefila et al., 2007). Argyris (2002) found that financial plans were thought of as weight procedures utilized by administration on directors. This knowledge would not encourage the best level of duty from the subordinates. In a participatory spending condition subordinates must not just partake in spending plan formulation,but they ought to alsobe part of the grave choices touchingon the business, sending and control of human and money related resources. This is important if the spending practice is not to be viewed as one-sided or pseudo-participatory, a training that slopes to incite less subordinate promise, evasion of obligation and little spending execution. 


\subsection{METHODOLOGY}

\subsection{Research Design}

Research configuration is the general arrangement for associating the calculated research issues to the germane and achievable exact research. Mugenda and Mugenda (2005) shows that exploration configuration verbalizes what information is required, what techniques will be utilized to gather and dissect this information, and how the greater part of this will answer the analysts question. The investigation will utilize a contextual investigation as its examination outline. As indicated by Cooper, and Schindler (2006) a contextual investigation is a capable research system that consolidates individual and (now and again) gather interviews with record examination and perception. It is utilized to comprehend occasions and their implications and procedures. Mugenda and Mugenda (2005) portray a contextual investigation as an inside and out examination of an individual, gathering, organization or marvel. A contextual investigation approach is appropriate to decide the elements that make a specific passage system great for the association under examination.

\subsection{Population of the Study}

According to Kombo and Tromp (2006), populace is a gathering of people, articles or things from which tests are taken for estimation, or, it is a whole gathering of people or components that have no less than one thing in like manner. The objective populace of the examination will be all the every one of the representatives and authorities of the Kisii County. Target populace is characterized as that populace to which an analyst needs to sum up the aftereffects of the examination.

\subsection{Sample and Sampling Procedure}

This examination will receive the stratified arbitrary inspecting strategy. Irregular testing gives an analyst a reasonable or agent perspective of the whole populace. What's more, this method empowers the specialist to have a top to bottom investigation and knowledge on the subject being contemplated (Merriam, 2003). A specimen must be painstakingly chosen to be illustrative of the populace and the analyst additionally needs to guarantee that the subdivisions involved in the examination are precisely provided food for. Arbitrary testing strategy will guarantee diverse subgroups in the Kisii County representatives and authorities are spoken to in the examination.

A specimen of 105 representatives and authorities will be drawn from among the County specialists and authorities. An example can be characterized as a limited piece of a measurable populace whose properties are to be concentrated to pick up data about the entire (Merriam, 2003). The sample in this review will be gotten utilizing the Israel recipe where a certainty level of $90 \%$ will be utilized which as indicated by Saunders, Lewis, and Thornhill (2005) is the level of conviction of the attributes gathered speaking to the qualities of the aggregate populace. A safety buffer of $8 \%$, which the exactness required by scientist for the appraisals produced using test will be utilized as well. Accordingly, a specimen size of 105 ought to be an agent of the all-inclusive community.

\subsubsection{Criteria for selecting sample size} Table1. Sample Size

\begin{tabular}{llll}
\hline Acc Accuracy (+/-) (Margin of error) & Confidence Level & & $99 \%$ \\
& $90 \%$ & $95 \%$ & 16576 \\
$\mathbf{1}$ & 6765 & 9604 & 4144 \\
$\mathbf{2}$ & 1691 & 2401 & 1848 \\
$\mathbf{3}$ & 752 & 1067 & 1036 \\
$\mathbf{4}$ & 413 & 600 & 663 \\
$\mathbf{5}$ & 271 & 384 & 166 \\
$\mathbf{1 0}$ & 68 & 96 & 41 \\
$\mathbf{2 0}$ & 17 & 24 & 46 \\
\hline
\end{tabular}

(Source: Researcher, 2019)

According to Israel (2009) and Mugenda and Mugenda (2003) the following formula for sample size determination should be used; $n=p(1-p)\left(\frac{z}{d}\right)^{2}$ Where:

$\mathbf{n}=$ sample size

$\mathbf{z}=$ the table value for the level of confidence, for instance $\mathbf{9 5 \%}$ level of confidence $=\mathbf{1 . 9 6}$ while $\mathbf{9 0 \%}$ level of confidence $=1.645$.

$\mathbf{d}=$ margin of error

$\mathbf{p}=$ proportion to be estimated, Israel (2009) and Mugenda and Mugenda (2003) recommends that if one doesn't know the value of $\mathrm{p}$ then one assumes $\mathrm{p}=0.5$.

Therefore, the sample size of this study is calculated as follows: 


$$
105=0.5(1-0.5)\left(\frac{1.645}{0.08}\right)^{2}
$$

\subsection{Data Collection}

The Research utilized bot optional and essential information. Auxiliary information was gotten from the Kisii County handbooks and records put away in the County's information base while essential information was gathered utilizing surveys which contained questions intended to evoke information as per the exploration questions. The polls was sent to the respondents under a survey sending letter joined by a presentation letter from the University. The survey contained both open and close finished inquiries. In the event of the nearby finished inquiries, a fivepoint Likert-sort scale, positioning from 1 (Strongly deviate) to 5 (Strongly concur) was utilized for every one of the variables with 5 being the most grounded/most noteworthy. The utilization of surveys is advocated as they offer a compelling method for gathering data from an expansive specimen in a limited capacity to focus time and at a diminished cost than different techniques.

\subsection{Data Analysis}

After information has been gathered through surveys, it was set up in preparation for examination by altering, dealing with clear reactions, coding, sorting and entering into Statistical Package for Social Sciences (SPSS Version 21) PC programming for analysis. Information was broken down utilizing both quantitative and subjective strategy for information analysis. In particular, enlightening measurements included frequencies while inferential insights included ANOVA and relapse analysis. The factual bundle for sociologies (SPSS) was utilized to direct illustrative and in addition inferential measurements. As indicated by Trochim (2006) elucidating measurements are utilized to depict the fundamental highlights of the information in an examination or study. They give basic rundowns about the specimen and the measures. Together with straightforward designs analysis, they shape the premise of intents and purpose each quantitative analysis of information. Moreover, according to Hsieh and Shannon (2005) subjective substance analysis is favoured and enables researchers to comprehend social reality in a subjective in logical way.

\subsection{FINDINGS \& DISCUSSIONS}

4.1 Legislation on Budget Implementation in Kisii County Government.

Table2. Descriptive Statistics for legislation on Budget Implementation

\begin{tabular}{|c|c|c|c|}
\hline Legislation & Mean & $\begin{array}{c}\text { Std. } \\
\text { Deviation }\end{array}$ & Analysis N \\
\hline $\begin{array}{l}\text { County Assembly Members delayed in formulating the County } \\
\text { Finance Bill. }\end{array}$ & 4.477 & 0.396 & 105 \\
\hline $\begin{array}{l}\text { The MCAs in this County have used statutes to hinder the } \\
\text { Governor's and the entire executive's dream in relation to budget } \\
\text { implementation. }\end{array}$ & 4.325 & .940 & 105 \\
\hline $\begin{array}{l}\text { Un-matching laws formulated by the County Assembly have made } \\
\text { it difficult to properly implement the County budget. }\end{array}$ & 4.198 & .860 & 105 \\
\hline $\begin{array}{l}\text { Legal progression in terms of formulation of laws concerning } \\
\text { budget implementation has not kept pace with the dynamism of the } \\
\text { devolved government. }\end{array}$ & 4.456 & 1.044 & 105 \\
\hline $\begin{array}{l}\text { The extent to which the County budget will be fully implemented } \\
\text { depends on the Laws formulated by the County Assembly. }\end{array}$ & 4.342 & .607 & 105 \\
\hline
\end{tabular}

The results in table 2 above shows that the respondents agreed that County Assembly Members delayed in formulating the County Finance Bill with (mean 4.477). The MCAs used statutes to hinder the Governor's and the entire executive's dream in relation to budget implementation with (mean 4.325), while Un-matching laws formulated by the County made it difficult to properly implement the County budge with (mean 4.198). Legal progression in terms of formulation of laws concerning budget implementation did not keep pace with the dynamism of the devolved government (mean 4.456), and in all the extent to which the County budget will be fully implemented depends on the Laws formulated by the County Assembly( mean 4.342). The smaller standard deviation relative to the respective mean implies that there is no significant difference between the sample means and populations mean is the appropriate model that represents the data.

Legislation variables that affect budget implementation in Kisii County government were then identified using factor analysis.

Factors (several legislative variables) were identified using factor analysis since they were perceived to affect budget implementation and were categorized legislation factors. The preliminary tests employed the use of Kaiser 
Mayer-Olkin (KMO) and Barlett's test. In this case, KMO measures the sampling adequacy which should be greater than 0.5 for a satisfactory analysis to proceed. Table 2 shows that the KMO measure is .664 which is significant at $\mathrm{p}<.001$, an indication that the Barlett's test of sphericity is significant.

Table 3 Kaiser-Meyer- Olkinand Bartlett's Test

\begin{tabular}{|c|c|c|}
\hline \multicolumn{3}{|c|}{ KMO and Bartlett's Test } \\
\hline Kaiser-Meyer-Olkin Measure & of Sampling Adequacy. & .664 \\
\hline & Approx. Chi-Square & 353.221 \\
\hline Bartlett's Test of Sphericity & df & 104 \\
\hline & Sig. & .000 \\
\hline
\end{tabular}

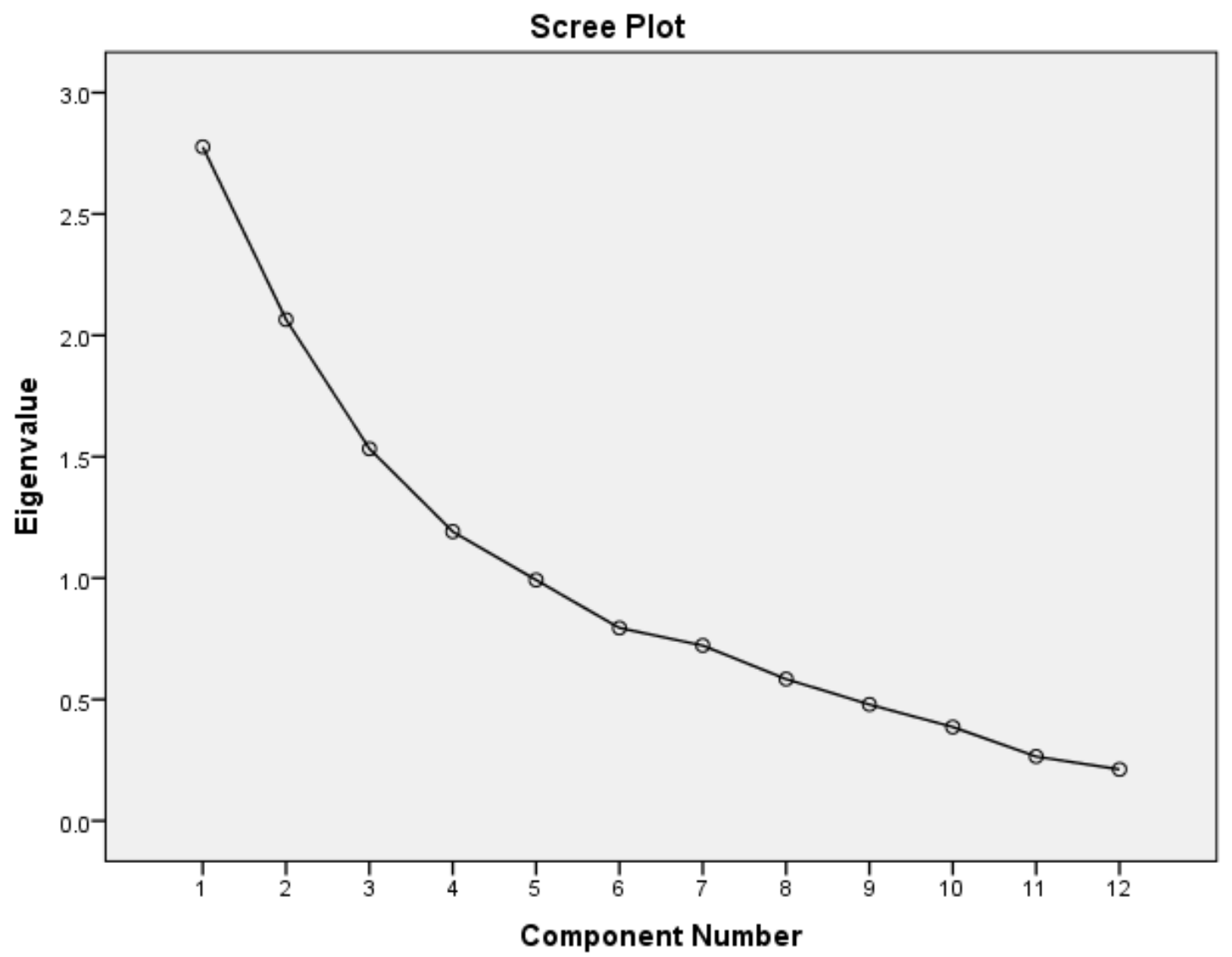

By graphing the eigenvalues the relative importance of each variable becomes apparent. There are a few variables with quite high eigenvalues and many variables have relatively low eigenvalues, and so this graph has a very characteristic shape. There is a sharp descent in the curve followed by a tailing off. The cut off point for selecting variables is at the point of inflexion of this curve. From the plot we can extract variables with eigenvalues above one. To establish the priority variables implementation of the budget, legislative variables were subjected to factor analysis procedure applying varimax as the method for rotation and principal component as a method for extraction of factor components. The results of the factor analysis are shown in table 3 of communalities above. The findings show that all legislative variables of extraction value above .650 as shown in the communality table 4 below affect budget implementation. 
Table 4 Communalities for legislation

\begin{tabular}{|c|c|c|}
\hline & Initial & Extraction \\
\hline County Assembly Members delayed in formulating the County Finance Bill. & 1.000 & .718 \\
\hline $\begin{array}{l}\text { The MCAs in this County have used statutes to hinder the Governor's and the } \\
\text { entire executive's dream in relation to budget implementation. }\end{array}$ & 1.000 & .694 \\
\hline $\begin{array}{l}\text { Un-matching laws formulated by the County Assembly have made it difficult to } \\
\text { properly implement the County budget. }\end{array}$ & 1.000 & .684 \\
\hline $\begin{array}{l}\text { Legal progression in terms of formulation of laws concerning budget } \\
\text { implementation has not kept pace with the dynamism of the devolved } \\
\text { government. }\end{array}$ & 1.000 & .701 \\
\hline $\begin{array}{l}\text { The extent to which the County budget was fully implemented depended on the } \\
\text { Laws formulated by the County Assembly. } \\
\text { Extraction Method: Principal Component Analysis. }\end{array}$ & 1.000 & .696 \\
\hline
\end{tabular}

The results in table 4 above show that all the variable were extracted since they had values above .065 . All the variables were extracted and merged to form legislation factor using transformation technique employing SPSS version 21 to form leadership factor and correlated with budget variables as shown in table 5 below.

Table 5 Correlations of legislation on budget implementation

\begin{tabular}{l|lc}
\hline \multicolumn{2}{l}{ Budget implementation } & \multicolumn{2}{l}{ Legislation } \\
\hline Absorption rate of fund & Pearson Correlation & $.421^{* *}$ \\
\cline { 2 - 3 } & Sig. (2-tailed) & .001 \\
\cline { 2 - 3 } & $\mathrm{N}$ & 105 \\
\hline \multirow{2}{*}{ Number of projects implemented } & Pearson Correlation & $.364^{* *}$ \\
& Sig. (2-tailed) & .050 \\
& $\mathrm{~N}$ & 105 \\
Proper documentation i.e. work plans, & Pearson Correlation & $.432^{* *}$ \\
procurement plans & Sig. (2-tailed) & .023 \\
& $\mathrm{~N}$ & 105 \\
Public satisfaction \& ownership & Pearson Correlation & $.453^{* *}$ \\
& Sig. (2-tailed) & .001 \\
& $\mathrm{~N}$ & 105 \\
\hline
\end{tabular}

*. Correlation is significant at the 0.05 level (2-tailed).

**. Correlation is significant at the 0.01 level (2-tailed).

The results in table 5 above show that legislation positively and significantly influence ; Absorption rate of fund, Number of projects implemented, Proper documentation i.e. work plans, procurement plans and Public satisfaction \& ownership at $\left(\mathrm{r}=.421^{* *}, \mathrm{P}<.01\right),\left(\mathrm{r}=.364^{* *}, \mathrm{p}<.05\right),\left(\mathrm{r}=.432^{* *}, \mathrm{p}<.05\right)$, and $\left(\mathrm{r}=.453^{* *}, \mathrm{p}<.01\right)$ respectively. All the variable under budget implementation were matched using transformation method using SPSS to form one factor called budget implementation and correlated with legislation factor as shown in table 6 below; Table 6 Correlation between legislative factor and budget implementation

\begin{tabular}{llc}
\hline & & Budget implementation \\
\hline \multirow{3}{*}{ Legislation } & Pearson Correlation & $.762^{* *}$ \\
& Sig. (2-tailed) & .004 \\
& $\mathrm{~N}$ & 105 \\
\hline
\end{tabular}

**. Correlation is significant at the 0.05 level (2-tailed).

Legislation positively and significantly influence budget implementation at $\mathrm{r}=.762 * *$ and $\mathrm{p}<.05$ significant level. Calculating the coefficient of determinant $\mathrm{R}$, legislation contributes $58.0 \%$ variability to budget implementation when other factors are held constant. 


\subsubsection{DISCUSSIONS}

4.1.2 Legislation on Budget Implementation in Kisii County Government.

The results of analysis showed that the respondent agreed that; County Assembly Members delayed in formulating the County Finance Bill, that the MCAs in the County had used statutes to hinder the Governor's and the entire executive's dream in relation to budget implementation, un-matching laws formulated by the County Assembly had made it difficult to properly implement the County budget, Legal progression in terms of formulation of laws concerning budget implementation had not kept pace with the dynamism of the devolved government and lastly they agreed that the extent to which the County budget would be fully implemented depended on the Laws formulated by the County Assembly.

Further analysis revealed that; Legislation positively and significantly influenced budget implementation at $\mathrm{r}=.462^{* *}$ and $\mathrm{p}<.05$ significant level. Calculating the coefficient of determinant $\mathrm{R}$, legislation contributes $21.3 \%$ variability to budget implementation when other factors are held constant.

These finding are in agreement with many scholars; Richard et al. (2001), argues that viable spending administration starts with an unmistakable appropriation of obligations and inside the legislature, and between the diverse levels of government, and a precisely adjusted division of forces between the official branch of governments and the parliament. For this reason, the lawful system must be obviously outlined. Rebecca et al. (2011), notes that the spending cycle commences with the planning strategy, where the government which has administrative oversight, plans for the utilization of the future year's assets as per approach needs. Odhiambo (2013), argues that County enactments controlling the conveyance of administrations by the separate offices are yet to be placed in place.

\subsection{SUMMARYOF THE FINDINGS, CONCLUSION AND RECOMMENDATION}

5.1. Summary of findings.

5.1.1 Legislation on Budget Implementation in Kisii County Government.

Legislation positively and significantly influence budget implementation at $\mathrm{r}=.462 * *$ and $\mathrm{p}<.05$ significant level. Calculating the coefficient of determinant $\mathrm{R}$, legislation contributes $21.3 \%$ variability to budget implementation when other factors are held constant.

\subsection{Conclusion}

Legislation positively and significantly influences budget implementation contributing $21.3 \%$ variability to budget implementation when other factors are held constant. Public participation positively and significantly influences budget implementation contributing 19.6\% variability in budget implementation when other factors are held constant.

\subsection{Recommendation}

The county assembly should speed up the sanctioning of all enactments relating to county government funds and administration conveyance to give an appropriate lawful structure to spending execution.

\section{REFERENCE}

American Public Human Services Association (2014). Budget and Finance Guidance; Implementation: How does an agency implement an effective approach to budget and finance?

Anthony, R.N. and Govindarajan, V. (2007) Management Control Systems (12th Edition). New York: McGraw Hill.

Auditor General of Canada (2010) Human Resource Capacity; Government of Nunavut: 2010 March Report of the Auditor General of Canada.

Babcock-Daley D., Wright S., Miracle K., Resta K., Amanda M., Rumberg M., Holsneck S. (2003). Strategic Workforce Planning: County of Fairfax, Virginia.

Carol Ebdon and Aimee L. Franklin (2005). Are we all touching the same camel? Exploring a model of participation in budgeting. The American Review of Public Administration, 35 (168), pp. 32-49.

Cooper, D.R. \& Schindler, P.S., (2006). Business Research Methods, 9 ${ }^{\text {th }}$, edition. McGraw-Hill Publishing, Co. Ltd. New Delhi-India.

Constitution of Kenya, 2010

GIZ (2010). Learning from the South: Participatory budgeting worldwide, an invitation to global cooperation," No. 25. Available at: http://www.buergerhaushalt.org/sites/default/files/downloads/LearningfromtheSouthParticipatoryBudgetingWorldwide-Study 0.pdf.

Hsieh \& Shannon (2005). Three Approaches to Qualitative Content Analysis: Sage Journal

Josh Lerner and Donato Secondo (2012). By the people, for the people: participatory budgeting from the bottom up in North America: Journal of Public Deliberation, 8(2).

Kombo, D, Tromp, D (2006): Proposal and Thesis Writing- An Introduction. Paulines Publications, Nairobi. 
Lakin J. (2013). Public Participation in Kenya: County Budget and Economic Forums - Principles and Options: Budget Brief No.21: International Budget Partnership.

Maskin E. and Sjostrom T. (2001). Implementation Theory:

Merriam, W. (2003). Collegite Dictionary. Springfied Massachusets: 11 Ed.

Mugenda, Olive M. \&Mugenda, Abel G. (2005). Research Methods: Quantitative and Qualitative Approaches, Acts Press, Nairobi-Kenya.

Nivek K. Thompson (2012). Participatory budgeting - the Australian way," Journal of Public Deliberation Vol. 8: Issue 2, article 5. Available at: http://www.publicdeliberation.net/jpd/vol8/iss2/art5; Accessed on March 22, 2014

Office of the Budget controller of Kenya Report, June 2013

Public Finance Management (PFM) (2013). Public Participation Under Kenya's New Public Financial Management Law and Beyond.http://internationalbudget.org/wp-content/uploads/PFM-Brief-.pdf. Accessed on March 22, 2014.

Stephanie McNulty (2012). An Unlikely Success: Peru's Top-Down Participatory Budgeting Experience. Journal of Public Deliberation: Vol. 8: Issue 2, article 4. Available at: http://www.publicdeliberation.net/jpd/vol8/iss2/art4. Accessed on March 22, 2014.

Trochim, W. M (2006). The research methods knowledge base (2 ${ }^{\text {nd }}$ ed). Cornell University: Atomic Dog Publishing.

Yan Wu and Wan Yeng (2012). Does participatory budgeting improve the legitimacy of the local government? A comparative case study of two cities in China," The Australian Journal of Public Administration Vol. 71 (2), 2012, pp. 122-135. 